\title{
Research on Teaching Strategy of Roadbed Structure and Construction Course Based on BIM Technology
}

\author{
Qing Wang ${ }^{1}$, Yongxiang Ren $^{2}$ \\ ${ }^{1}$ Henan Communication Vocational Technology College, Zhengzhou 450000, Henan, China. \\ E-mail: 15768403@qq.com \\ ${ }^{2}$ Xuchang Vocational Technical College, Xuchang 461000, Henan, China.
}

Abstract: The roadbed structure and construction course is a compulsory course for the major of road and bridge engineering technology in higher vocational colleges. The content of the course is theoretical, the formula is complex, and it is difficult to understand, which increases the difficulty of students' learning, especially under the traditional "indoctrination" theoretical teaching mode, Classroom teaching efficiency is low, and students tend to lose interest and confidence in learning. With the application of BIM technology, students were visually shown the relationship between subgrade structure and construction components and construction links, with remarkable results. This article focuses on the problems related to the teaching of roadbed structure and construction courses based on BIM technology.

Keywords: BIM Technology; Roadbed Structure and Construction; Course Teaching; Specific Countermeasures

With the continuous acceleration of China's urbanization process, the transportation industry has achieved rapid development, the number of traffic projects has continued to increase, and the scale has continued to grow. Roadbed structure and construction courses involve a lot of practical teaching content, but teachers still use two-dimensional drawings and construction On-site photos are regarded as the main material, lacking systematic and intuitiveness, and it is difficult to stimulate students' interest and enthusiasm in learning. Next, talk about some thoughts on the application of BIM technology in the teaching of roadbed structure and construction courses.

\section{Problems in the teaching of roadbed structure and construction courses}

At this stage, there are still problems in the teaching of roadbed structure and construction courses, such as lack of systemicity, perfection and continuity; difficulty in teaching and low level of practical teaching.

First, the teaching of roadbed structure and construction courses covers three major areas: highway construction, tunnel construction and bridge construction. First, in the teaching of highway engineering construction, roadbed and pavement engineering are at the core. Subgrade engineering is a belt-shaped structure, and pavement engineering is a layered structure. In specific teaching, teachers need to explain the theoretical knowledge of subgrade engineering first, and then introduce the core content of subgrade excavation, filling, drainage and protection, and then explain the pavement Construction content of base and surface. Secondly, the bridge and tunnel engineering is very complex, the construction steps are complicated, difficult, and demanding, and the higher vocational colleges cannot simulate the real construction site, resulting in students not being able to understand and master the content of bridge and tunnel engineering and construction courses through personal experience.

Second, generally speaking, highway engineering has the characteristics of long construction period, wide construction scope, long construction route, and many construction points. Although in the classroom teaching process, teachers give full play to the role of multimedia information technology. However, there are many limiting factors in offline practice, making it difficult to improve the quality of practice teaching. As a result, students cannot fully understand the overall construction process of highway engineering, and cannot effectively connect relevant knowledge points indeCopyright $\odot 2020$ Qing Wang et al

doi: $10.18282 /$ le.v9i6.1302

This is an open-access article distributed under the terms of the Creative Commons Attribution Non-Commercial License

(http://creativecommons.org/licenses/by-nc/4.0/), which permits unrestricted non-commercial use, distribution, and reproduction in any medium, provided the original work is properly cited. 
pendently. There are often problems of small loss and large, which seriously reduces the overall teaching quality and level of the course.

Third, with the rapid development of network information technology, the update speed of roadbed structure and construction related knowledge is very fast, but the update speed of teaching materials is slow, which is difficult to meet the teaching needs. With the rapid development of society, China attaches great importance to the development of the transportation industry, and has increased its funding support for the construction of transportation infrastructure. Based on this, various new technologies and techniques for highway construction are emerging. However, the subgrade structure and construction course materials are very slow to update new technologies, new processes, and new materials, and they are mostly displayed through text and pictures. Students cannot understand the overall construction process and technology through these, resulting in poor teaching effects.

\section{Specific countermeasures for the teaching of roadbed structure and construction courses based on BIM technology}

\subsection{Establish correct thinking and cognition}

A lot of teaching practice has proved that in the course of teaching roadbed structure and construction, if the traditional "instillation" theory teaching mode is adopted and the importance of practical teaching is ignored, students will not be able to objectively perceive the engineering structure and apply what they have learned. Based on this, teachers in higher vocational colleges should actively change their teaching concepts and reform the shortcomings of the traditional teaching model. As a college, it is necessary to introduce policies and systems based on actual conditions to guide teachers to establish lifelong learning concepts, master advanced technologies, accumulate a large amount of practical experience based on solid professional theories, and develop new teaching models to visualize abstract and obscure theoretical knowledge, Specific and visualized, so as to continuously improve the quality and level of teaching.

\subsection{Innovative course teaching mode}

First, in the new era, teachers must fully understand the many problems exposed in teaching of roadbed structure and construction courses, insist on advancing with the times, and infiltrate diversified information technology factors in the teaching process to truly reproduce the road in all directions and multiple angles. The construction process of the project and the use of advanced technology can build a three-dimensional data model of complex and obscure project information, so that students can visually and intuitively grasp the entire process of highway construction. In this way, students improve their practical ability in the real engineering project construction situation. Secondly, we must focus on helping students solidify their theoretical knowledge base and professional skills. As teachers, we must strengthen information collection and improve the comprehensiveness and effectiveness of information models. In addition, higher vocational colleges should insist on taking BIM technology as the core and innovating curriculum teaching models. To improve the requirements for teachers' comprehensive ability, teachers are required to fully grasp the construction technology, construction process and construction technology of subgrade engineering, and be able to use these building information model technologies proficiently to build a "double-qualified" teacher team, continuously enhance the strength of teachers, and continuously improve teaching perfection Sex, continuity and effectiveness.

Second, focus on enhancing practical teaching capabilities. Before teaching, teachers should establish a complete three-dimensional spatial data model to dynamically display all project information in the life cycle of highway projects in real time. It also focuses on introducing the core content of highway engineering construction, giving full play to the role of the three-dimensional model, and guiding students to successfully collect information and master knowledge points.

Third, adopt simulation teaching mode. As we all know, the three-dimensional spatial data model based on BIM technology has the advantages of visualization and simulation, which create good conditions for simulation teaching. For example, in the teaching process, teachers simulate the application process of bridge engineering construction technology to guide students to systematically, comprehensively and intuitively master the engineering construction technology and process; use the dynamic and three-dimensional display of collaborative management to guide students to fully grasp the collaboration in the engineering management process Management operation steps. Secondly, in the process of practical teaching, teachers should ask students to independently and cooperate to build a three-dimensional spatial data model, guide students to understand the construction process and construction technology of different scales and 
types of highway engineering projects in the process of building the model, and stimulate students' interest and enthusiasm for learning, Improve professional comprehensive ability, and then be able to meet the job requirements of future positions.

\subsection{Give full play to the visual characteristics of BIM technology to cultivate students' review ability}

After the three-dimensional spatial data model is established, it must be used to visualize the demonstration based on different types and different construction stages of the same type of projects. As one of the basic characteristics of building information model technology, visualization plays an important role in the compilation of construction project planning. Secondly, the building information model technology has an irreplaceable role in technical disclosure. During the engineering design process, the building information model technology can promote the integration of the three-dimensional spatial data model and the LumenRT model, and browse all engineering projects from all-round and multi-angles, ensuring that the construction party and the owners can fully and vividly understand the basic situation and geographical location of the project Etc., to lay a solid foundation for engineering project planning. In addition, in the construction process, the visualization function of the three-dimensional spatial data model is conducive to promoting the quality and level of communication between all parties, improving the degree of coordination and cooperation, and improving the overall construction quality and level.

With the in-depth reform of China's higher vocational education system, BIM technology has become an indispensable part of the practical teaching of road and bridge technology professional courses. The application of the three-dimensional spatial data model established by BIM technology can help students to master engineering in all directions and multiple angles. Project characteristics, construction technology and process information, cultivate students' good review ability, and apply what they have learned in the future work process.

\subsection{Establish a complete engineering structure BIM laboratory}

Compared with other professional courses, the course of roadbed structure and construction is more practical. To improve the effectiveness of practical teaching, you need a complete experimental platform and hardware equipment to support. As a vocational college, an engineering structure BIM laboratory should be established according to the actual situation. Students can use BIM technology to integrate the professional knowledge system that they have learned, guide students to sort out the correct understanding of engineering structure, and enhance students' ability to use professional knowledge. Continuously improve the quality and level of teaching. At the same time, it is necessary to develop high-quality engineering structure teaching materials through BIM technology, organize students to participate in engineering structure and construction simulation production, carry out engineering structure knowledge system teaching for freshmen students, understand the construction process and design process of engineering structure, and learn the theory for students comprehensively A solid foundation of knowledge and professional practice.

\section{Conclusion}

In summary, in the course of roadbed structure and construction courses, the use of BIM technology to establish a three-dimensional spatial data model is conducive to eliminating the drawbacks of the traditional "indoctrination" theoretical teaching mode. Through the visualization, simulation and adjustment of the three-dimensional model Such advantages as concrete, visualized, and intuitive abstract and obscure theoretical knowledge are conducive to reducing the difficulty of understanding knowledge, while also effectively stimulating students' interest and enthusiasm in learning, and focusing on classroom learning, thereby continuously improving the quality of professional teaching and Level, cultivate high-quality, high-quality applied talents.

\section{References}

1. Zhu Rongfen, Huang Long. Architectural drawing and construction course teaching based on BIM technology [J]. Chi Zi, 2019(015): 84.

2. Yang Bo, Jiang Pingjiang, Chen Yanru. The application of BIM technology in the teaching reform of bridge construction courses [J]. Journal of Liaoning Vocational College, 2017, 19(002): 52-55.

3. Jin Jie, Bi Yanzhao. Discussion on the application of BIM technology in engineering structure teaching[J]. Real Estate, 2019(17): 19-2 